\title{
Resource-saving materials based on hydrophobic low water demand binder
}

\author{
EvgeniyaTkach $^{1, *}$, and Yuliya Sadchikova ${ }^{1}$ \\ ${ }^{1}$ Moscow State University of Civil Engineering, Yaroslavskoe shosse, 26, Moscow, 129337, Russia
}

\begin{abstract}
This research have shown that the developed composition and method for preparation of granulated organic-mineral admixture S-3SSA allow production in drum granulator of cement materials modifier with desired properties using proposed mixing procedure for the admixture ingredients which include, mass. \%: superplasticizer S-3 - 10; soap stock - 20; salt of inorganic acid -30 and ash -40 . On the basis of laboratory studies, a ratio of the components included in the molding compound for pressed bricks with improved physical and technical properties was defined. Optimal composition of the molding compound should contain the following, mass. $\%$ : binder - 10 ; clay - 5; sand - 82 ; water - 3 . A technological procedure for production of pressed brick based on gypsum binders of low water demand (GLWDB) was developed and technological production parameters were defined: moulding compound moisture content - 6\%; raw material strength - 0.4 MPa; specific pressure - about $15 \mathrm{MPa}$, curing conditions - natural. Basic physical and technical properties of pressed brick based on GVNV-50S were identified and studied. Strength kinetics, MPa: 1 day $6.8 ; 3$ days $-12.3 ; 28$ days -27 ; density $-1950 \mathrm{~kg} / \mathrm{m}^{3}$; softening coefficient equal.
\end{abstract}

\section{Introduction}

Nowadays and in the future, one of the effective methods for production process control and quality management is use of multifunctional modifiers of cement systems and binders such as LWDB (low water demand binders).

In this regard, there is an objective need to develop a raw material mixture for production of pressed bricks, significantly different in their properties from the known analogues.

Taking into account the data given in scientific and technical sources, it can be stated that development of new compositions and methods for production of environmentally friendly small-piece items with specified properties intended for wall construction is necessary. At the same time, it is necessary to use such technical solutions that would ensure exclusion of energy-intensive technological reworking (roasting, drying) and would allow use for bricks local raw materials (sand, ash, clay), low water demand binders and chemical additives (modifiers).

\footnotetext{
* Corresponding author: ev tkach@mail.ru
} 


\section{Problems}

The purpose of this research was to develop compositions and method for pressed wall materials production on the base of fine-grained concrete with a hydrophobic binder of low water demand.

It is known that for the small-piece pressed wall materials production, in particular, bricks, fine-grained molding compounds based on Portland cement and quartz sand are used.

However, for such molding compounds, it is not possible to regulate growth of the material strength, values of capillary suction, water absorption, thermal properties and also frost resistance that limits to some extent application of such bricks in construction. Therefore, the molding compound composition should include a component in which the ingredients of the proposed organic-mineral admixture will provide a synergistic effect causing improvement of viscoplastic properties of dispersed systems and quality and strength of the cement stone. And for improvement of molding properties and for regulation of physical and technical properties of hardened bricks, and also for expansion of the raw material base it is necessary to provide for adding to the moulding compound composition a clay component and ash.

Creation of such a molding compound composition will ensure creation of environmentally friendly and resource-saving production of small-piece pressed materials with desired properties.

An important step in the technology and application of fine-grained concrete was development of compositions for production of such material on the base of low water demand binders (LWDB) [1, 2, 3].

As can be seen from the scientific and technical sources, binders of low water demand (LWDB) are produced by means of the cement remilling at presence of surface-active substances that facilitate the remilling process and prevent aggregation (caking) of crushed cement particles.

Increased amounts of superplasticizers in the form of dry powder are used as surfaceactive substances (surfactants) for LWDB. It is such remilling (mechanical and chemical activation) of Portland cement that leads to a high activity and low water demand of the binder $[4,1,2]$. These properties make difference between LWDB and fine ground cement. It should be noted that the fine-milled cements, which were previously produced, have a high water demand, in contrast to LWDB which has low normal density of cement paste; this indicator is $20-30 \%$ lower than the normal density of the original Portland cement.

The binder of low water demand allows reducing cement consumption by 2-3 times at production of concrete and reinforced concrete products and structures in comparison with conventional cement. This significantly increases the concrete strength, reduces production complexity, intensifies mold forms turnover and concreting rate due to acceleration of the cement stone hardening [1].

Use of LWDB allows expanding concrete assortment, in particular, concretes characterized by high water and frost resistance, as well as significantly expanding possibility of fine concrete application.

All said predetermines high economic efficiency when using a binder of low water demand in production of building materials $[4,1,2]$.

However, the binder of low water demand (LWDB) has significant disadvantages: loss of activity during transportation and storage, caking ability and relatively high cost due to use of rear expensive dry superplasticizer S-3. 


\section{Results}

Currently, use of chemical admixtures is a unique mean for control the technological process of new binders production, including binders of low water demand (LWDB).

LWDB is a hydraulic binder made of Portland cement clinker or Portland cement and its varieties, mineral admixtures, gypsum stone and dry modifier, including organic component based on naphthalene sulfates, by means of joint mechanical and chemical treatment in specially regulated conditions $[2,5]$.

However, currently, there are a number of objective factors that limit large-scale LWDB production. These include, first, a limited volumes of dry superplasticizer S-3 production, and also the superplasticizer cost. Drying the superplasticizer solution in spray dryers leads to significant rise in price, almost 2 times.

In this regard, to produce large amount of LWDB, a necessity arises to use liquid superplasticizer S-3 produced in sufficient quantities.

Analysis of S-3 superplasticizer use in concrete production shows that solutions with concentration of $20-40 \%$ are mainly produced. This factor is dominant in preventing widespread use of superplasticizers $[6,7,8,9]$.

It should be noted that, in the process of superplasticizer $\mathrm{S}-3$ production, such secondary products of coke production are used as naphthalene, sulfuric acid solution, and also formaldehyde $[10,11,9,12,13,15,16,17,18]$.

However, granulated additives made at coke production which include hydrophobizing ingredients and superplasticizer S-3 [14] do not allow production of such LWDB which provides sufficient increase in the cement concrete strength necessary for technology of concrete and reinforced concrete items production without heat treatment.

In this regard, we propose to add hardening accelerators in the form of salts of inorganic acids: calcium chloride, sodium nitrite, calcium nitrite, magnesium nitrite, into the granular additives.

It should be noted that complex modifiers consisting of surfactants and salts of inorganic acids cause a synergy (mutual reinforcement) effect increasing workability of cement systems, hardening rate and cement materials strength.

The developed compositions and method for preparation of granular organic-mineral admixtures (S-3SSA) allow production in drum granulator of cement materials modifier with desired properties using proposed procedure of its ingredients combining.

Table 1. Compositions of granulated admixtures

\begin{tabular}{|l|c|c|c|}
\hline \multirow{2}{*}{ Name of component } & \multicolumn{3}{|l}{$\begin{array}{l}\text { The component content in compositions, } \\
\text { mass fraction, \% (for waterless products) }\end{array}$} \\
\cline { 2 - 4 } & S-3A & S-3SA & S-3SSA \\
\hline S-3 & 25 & 17 & 10 \\
\hline Soap stock & - & 34 & 20 \\
\hline Ash & 75 & 49 & 40 \\
\hline $\begin{array}{l}\text { Inorganic acid salts: sodium or potassium or } \\
\text { magnesium nitrite; calcium chloride; sodium } \\
\text { thiosulfate }\end{array}$ & - & - & 30 \\
\hline
\end{tabular}

Values of drum rotation speed and mixing time for optimally selected ratio of the additive ingredients necessary for the granulation process were defined. The procedure was proposed for formation of the additive granules (S-3SSA) composed of, mass \%: superplasticizer S-3 - 10; soap stock - 20; salt of inorganic acid - 30 and ash -40 . 
Table 2. Technological parameters of granulated admixtures

\begin{tabular}{|c|c|c|c|c|}
\hline $\begin{array}{c}\text { Composition } \\
\text { № }\end{array}$ & $\begin{array}{c}\text { Ratio of the solu- } \\
\text { tion components: } \\
\text { ash-entrainment }\end{array}$ & $\begin{array}{c}\text { Drum rotation speed, } \\
\text { rpm }\end{array}$ & $\begin{array}{c}\text { Mixing time t, } \\
\text { min }\end{array}$ & $\begin{array}{c}\text { Residue of non- } \\
\text { granulated material, \% }\end{array}$ \\
\hline 1 & $10: 90$ & 20 & 15 & 10 \\
\hline 2 & $20: 80$ & 40 & 12 & 5 \\
\hline 3 & $30: 70$ & 50 & 10 & - \\
\hline 4 & $40: 60$ & 40 & 7 & $\begin{array}{l}* \text { material adheres to } \\
\text { the drum walls }\end{array}$ \\
\hline 5 & $45: 55$ & 30 & 7 & $\begin{array}{l}\text { ** composition is not } \\
\text { granulated }\end{array}$ \\
\hline
\end{tabular}

The obtained optimal emulsion/ ash ratio (treger) equal to 30: 70 (composition No.3) was used as a basic for preparation of a granular additive containing inorganic acid salts.

The scheme of formation of granules, adsorption layers and adhesion is shown in the Figure 1.

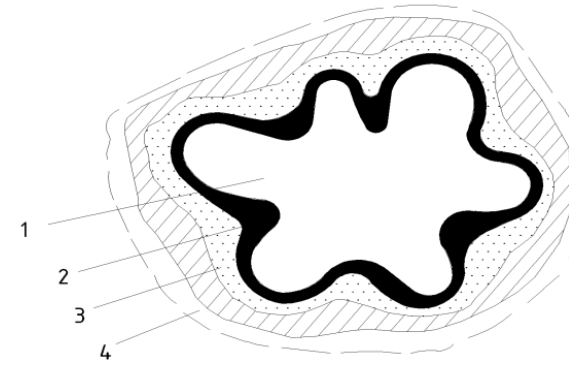

1 - ash (substrate or treger);

2 - adsorption layer of direct emulsion (first layer of soap stock and superplasticizer S-3);

3 - sticking (rolling) layer consisting of salts of inorganic acids;

4 - "protective" layer of soap stock and superplasticizer S-3.

Fig. 1. Scheme of admixture granules formation in cement materials

It can be seen in Figure 1 that the granulator-mixer of forced action does not allow production of granular admixture with the required quality (S-3SSA) which includes saltelectrolyte; in this granulator, granular fine-grained mixture of the admixture ingredients is formed; and hygroscopicity of salts-electrolytes leads over time to grains caking and to difficulties of using such an admixture in production.

Water-repelling organic-mineral additive - S3SSA added into GUNV-50C shortens curing time by almost 2 times in comparison with ordinary Portland cement.

Table 3. Curing time for binders of low water demand

\begin{tabular}{|c|c|c|c|c|c|}
\hline № & \multirow{2}{*}{ Binder type } & \multirow{2}{*}{ Addition type } & \multirow{2}{*}{$\begin{array}{c}\text { Content, \% of } \\
\text { binder mass }\end{array}$} & \multicolumn{2}{|c|}{ Curing time, hour-min } \\
\cline { 5 - 6 } & & & 1 & $1-35$ & $3-10$ \\
\hline 1 & VNV-50 & S-3 & 4 & $1-40$ & $3-20$ \\
\hline 2 & VNV-50 & S-3A & 4 & $1-45$ & $3-35$ \\
\hline 3 & GVNV-50 & S-3SA & 4 & $1-15$ & $3-00$ \\
\hline 4 & GVNV-50S & S-3SSA & 4 & $2-40$ & $8-50$ \\
\hline 5 & $\begin{array}{c}\text { Portland cement } \\
\text { TcEMI32,5N }\end{array}$ & No addition & 0 & & \\
\hline
\end{tabular}


It was found that the produced GVNV-50S has hydrophobic properties which ensures time stability for not only activity of the cement, but also for activity of other salts of inorganic acids, and prevents the powdered material caking.

Reduction by about 3 times of VNV-50S capillary suction and water absorption indicators in comparison with the ordinary Portland cement, that is due to hydrophobization of the pores and capillaries mesh inner surface in accordance with the theoretical provisions by $\mathrm{M}$. I. Kherovich was observed.

It was found that the LWDB tested at the age of 28 days has a clinker fund. Addition into LWDB composition of hydrophobic organic-mineral ingredients leads to some increased "consumption" of the clinker fund due to the synergy effect, electrolyte-salt hydration reactions with the binder.
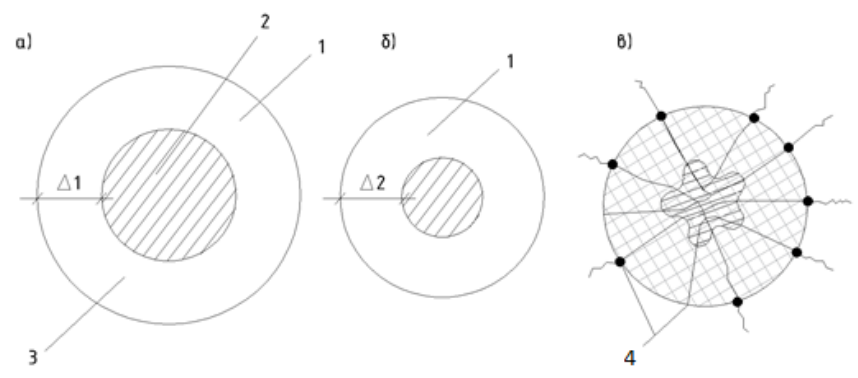

$\mathrm{a}$ - CEM I $32.5 \mathrm{~N}$ without additions; $\mathrm{b}$ - VNV-50 (1\% S-3); c- GVNV-50 (4\% S-3SSA); 1 - hydrated grain binder; 2 - clinker fund; 3 - depth of hydration zone; 4 - hydrophobisator in the form of a mesh.

Fig. 2. Scheme of clinker fund "preservation" in binder grains

A scheme of clinker fund "preservation" in the binder GVNV-50S grains, which develops scientific knowledge on hydrophobic LWDB production, was proposed.

Study of the cement stone microstructure has shown that the cement on the base of GVNV-50S has a more dense structure; pores in these samples are of a regular geometric shape and distributed evenly throughout the volume. Reduced pores cross-section should be considered the most important consequence of modification of structure of cement stone based on the hydrophobic binder with low water demand.

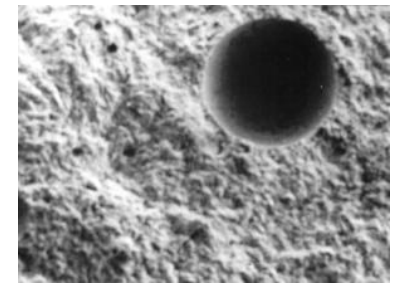

a)

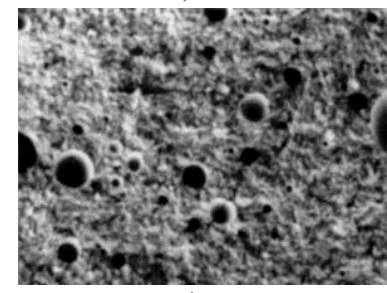

c)

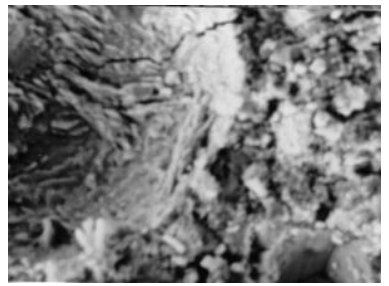

b)

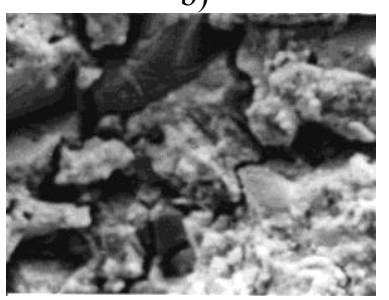

d) 


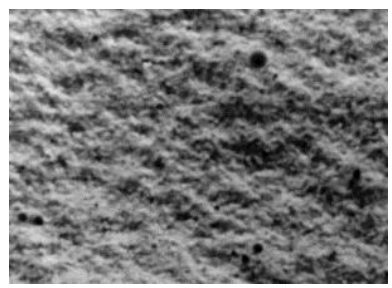

e)

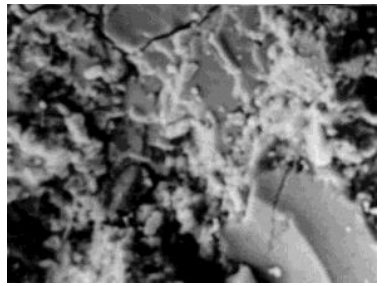

f)

$\mathrm{a}$ and $\mathrm{b}-$ Portland cement CEM I $32.5 \mathrm{~N}$; $\mathrm{c}$ and $\mathrm{d}-\mathrm{VNV}-50$ (admixture $-1 \%$ of $\mathrm{S}-3$ ); e and $\mathrm{f}-\mathrm{GVNV}-50 \mathrm{~S}$ (admixture $-4 \%$ of S-3SSA)

Fig. 3. Microstructure of cement stone

Physical and technical properties of the resulting brick are given in Table 4.

Table 4. Physical and technical properties of the pressed brick made of fine-grain concrete on the base of hydrophobic binder with low water demand (GVNV-50C)

\begin{tabular}{|c|c|c|c|c|c|c|c|c|c|c|c|c|}
\hline \multirow[t]{3}{*}{$\begin{array}{l}\text { Type of } \\
\text { binder }\end{array}$} & \multicolumn{4}{|c|}{$\begin{array}{l}\text { Composition } \\
\text { of raw mix- } \\
\text { ture }\end{array}$} & \multirow[t]{3}{*}{$\begin{array}{l}\text { Density, } \\
\mathrm{kg} / \mathrm{m}^{3}\end{array}$} & \multirow[t]{3}{*}{$\begin{array}{l}\text { Water ab- } \\
\text { sorption, \% }\end{array}$} & \multicolumn{4}{|c|}{$\begin{array}{l}\text { Compressive strength, } \\
\text { VGf }\end{array}$} & \multirow{3}{*}{$\begin{array}{l}\text { Frost re- } \\
\text { sistance, } \\
\text { cycles, } \\
\text { not less } \\
\text { than }\end{array}$} & \multirow{3}{*}{$\begin{array}{l}\text { Coeffi- } \\
\text { cient of } \\
\text { thermal } \\
\text { conduc- } \\
\text { tivity, } \\
\mathrm{W} / \mathrm{m}^{\circ} \mathrm{C}\end{array}$} \\
\hline & \multirow[b]{2}{*}{$\begin{array}{l}\overline{\mathrm{\theta}} \\
. \\
0\end{array}$} & \multirow[b]{2}{*}{$\frac{\mathrm{d}}{\mathrm{J}}$} & \multirow[b]{2}{*}{ Z्ञ } & \multirow[b]{2}{*}{$\begin{array}{l}\overline{ \pm} \\
\frac{\pi}{\pi} \\
3\end{array}$} & & & \multirow{2}{*}{$\begin{array}{l}\text { After } \\
\text { molding }\end{array}$} & \multicolumn{3}{|c|}{ Age, days } & & \\
\hline & & & & & & & & 1 & 7 & 28 & & \\
\hline $\begin{array}{l}\text { GVNV- } \\
50 \mathrm{C}\end{array}$ & 10 & 5 & 82 & 3 & 1950 & 6.0 & 0.44 & 6.8 & 18.0 & 27.0 & 50 & 0.9 \\
\hline $\begin{array}{l}\text { CEM I } \\
32.5 \mathrm{~N}\end{array}$ & 10 & 7 & 75 & 8 & 2000 & 11 & 0.3 & 2.0 & 7.9 & 14.2 & 30 & 0.94 \\
\hline
\end{tabular}

It can be seen from the obtained results that the strength of raw material based on GVNV-50S allows removal of products from the mold for semi-dry SM 1085 brick pressing and put them in stacks for aging; then, at 1 day age, this brick reaches a strength of about 6.5-7.5 $\mathrm{MPa}$ which makes it possible to ship the products to consumer and to transport to the construction site.

\section{Conclusions and recommendations}

At present, the main task of the construction industry is application of new resource-saving and energy-saving technologies for production of building materials, providing competitive products, including high quality and relatively low cost bricks by exclusion of thermal processes and use of local raw materials and industrial waste, taking into account environmental requirements.

The developed composition and method for preparation of granular organic-mineral admixture S-3SSA allows production in the drum granulator of the additives using proposed mixing procedure for admixture ingredients, which include the following, mass \%: superplasticizer S-3 - 10; soap stock - 20; salt of inorganic acid - 30 and ash -40 .

Duration of mechanical and chemical treatment of the binder ingredients with admixture was defined - $60 \mathrm{~min}$ - that makes it possible to produce GVNV-50S with a specific surface area of $4500 \mathrm{~cm}^{2} / \mathrm{g}$ and normal density of cement paste $19 \%$. It is found out that the low 
water demand binder GVNV-50S ensures preservation of clinker activity and prevents the powdered material caking.

A ratio of components included in the molding compound for production of pressed bricks with improved physical and technical properties was defined by the result of laboratory studies. Optimum composition of the molding compound should contain the following, $\%$ mass: binder - 10; clay - 5; sand - 82; water - 3. Developed technological scheme for production of pressed brick with GLWDB and technological production parameters were defined: moisture content in the moulding compound $=6 \%$; raw material strength -0.4 $\mathrm{MPa}$; specific pressure - about $15 \mathrm{MPa}$, conditions of hardening are natural.

Basic physical and technical properties of pressed brick based on GVNV-50S were identified and studied. Kinetics strength, MPa: 1 day $-6.8 ; 3$ days $-12.3 ; 28$ days -27 that eliminates the need for heat and moisture treatment; density-1950 kg $/ \mathrm{m}^{3}$; according to coefficient of thermal conductivity, the brick can be reckoned as "ineffective" wall materials; softening coefficient equal to 0.95 make it possible to refer the material as "waterresistant". Hydrophysical properties of the developed pressed brick GVNV-50S allow recommending its use for masonry foundations and basements located below the waterproofing layer.

All tests were carried out using research equipment of The Head Regional Shared Research Facilities of the Moscow State University of Civil Engineering (RFMEFI59317X0006).

\section{References}

1. N.N. Dolgopolov, M.A. Sukhanov, A.N. Lorettova, Concretes with a binder of low water demand (TcMIPKS, Moscow, 1991)

2. N.N. Dolgopolov, M.A. Sukhanov, A.N. Lorettova, A new type of cement binder - low water demand binders and ways of application (TcMIPKS, Moscow, 1992)

3. Yu.M. Bazhenov, Concr. techn., 3-4, 68, (2012)

4. N.N. Dolgopolov, M.A. Sukhanov, S.V. Fedorov, V.S. Shestoperov, Cement, 1, 16, (1990)

5. M.I. Khigerovich, A.P. Merkin, Physical-chemical and physical methods for analysis of building materials (Moscow: Higher school,1968)

6. E.V. Tkach, Proc. of the Univ., 1, 18, (2005)

7. M.O. Korovkin, Constr. and reconstr., 2, 84, (2011)

8. D.N. Nikolaev, P.S. Olyunin, K.A. Lebedev, Concr. techn., 10(99), 8, (2014)

9. L.Y. Kramar, B.Y. Trofimov, T.N. Chernykh, A.A. Orlov, K.V. Shuldyakov, Build. mat., 11, 21, (2016)

10. Yu.M. Bazhenov, Vestnik MGSU, 2, 94, (2013)

11. E.V. Tkach, Concr. techn., 7-8, 44, (2011)

12.E.V. Tkach, V.M. Dronov, Proc. of the Univ., 2, 57, (2005)

13. B.G. Skramtaev, P.F. Shubenkin, Construction and military engineering materials (Moscow, VIA publ., 1958)

14. V.S. Izotov, Yu.A. Sokolova, Chemical additives for concrete modifying (Moscow: Paleotip, 2006)

15. E.V. Tkach, V.S. Semenov, S.A. Tkach, T.A. Rozovskaya, Procedia Engineering, 111, $763(2015)$

16. E. Velichko, E. Tshovrebov, V. Semenov, MATEC Web of Conferences, 86, 04034 (2016)

17. S. Pashkevich, A. Pustovgar, A. Adamtsevich, A. Eremin, Applied Mechanics And Materials, 584-586, 1659 (2014)

18. V.N. Yarmakovsky, A.P. Pustovgar, Procedia Engineering, 111, 864 (2015) 